\title{
Model for Deflection Analysis in Cantilever Beam
}

\author{
Kolawole Adesola Oladejo, Rahaman Abu, and Olufemi Adebisi Bamiro
}

\begin{abstract}
Exposure to Finite Element Method is beneficial to undergraduate engineering students; and educators have an obligation to introduce students to modern engineering tools. However, teaching of the course is computational intensive and existing propriety software are very expensive. Different approaches to introducing students to the FEM have been proposed. Existing approaches make use of learning modules of commercial Finite Element Analysis (FEA) packages such as ANSYS, ABAQUS, COMSOL Multiphysics, ALGOR, JL AutoFEA Analyzer and PRO/MECHANICA. This paper presents an in-house developed finite-element-based computer model via the virtual work principle using Linear Strain Triangular (LST) elements for deflection analysis on cantilever beam. The validation and capability characteristics was demonstrated by applying it to a cantilever beam, subjected to a point load, using both coarse (4-element) and fine (10element) meshes. The model gave results very close to those obtained analytically; the 10-element mesh gave better results than the 4-element mesh. The model has made the analysis more flexible, and also made visualization and presentation of results easier for better judgment. It facilitates the presentation of the basic rules which govern FEA and helps in the learning of different aspects of the numerical technique; hence the model will serve as reliable tool in undergraduate engineering programme.
\end{abstract}

Index Terms-Cantilever Beam; Finite Element; Modelling; Plane Elasticity.

\section{INTRODUCTION}

Finite Element Method (FEM) is a numerical technique for finding approximate solutions of Partial Differential Equations (PDE) as well as integral equations. The solution approach is based either on eliminating the differential equation completely, or rendering the PDE into an approximately system of ordinary differential equations, which are then numerically integrated using standard technique such as Euler's method, Runge-Kutta, etc. Plane elasticity problems involve continua that are loaded in their plane. Where the continuum is loaded by forces normal to the plane, out-of-plane displacements, (for instance bending of a plate) are induced. Plane elasticity problems may be separated into two classes, namely plane stress problems and plane strain problems. In a plane stress problem, the continuum (such as a plate) is thin relative to other dimensions, and stresses normal to the plane are neglected. Problems in this category include diaphragm plates in box sections and plate girder webs where the applied loads are in

Published on December 18, 2018

K. A. Oladejo is with the Department of Mechanical Engineering, Obafemi Awolowo University, Ile-Ife, Nigeria (e-mail: wolesteady@yahoo.com).

R. Abu is with the Department of Mechanical Engineering, University of Ibadan, Nigeria (e-mail: aburahaman@yahoo.com).

O. A. Bamiro is with the Department of Mechanical Engineering, University of Ibadan, Nigeria (e-mail: oabamiro@yahoo.com). the plane of the member. In a plane strain problem, the strain normal to the plane of loading is assumed to be zero. Cantilever beam with a point load at the extreme end is a case of plane elasticity problems that is subjected to finite element analysis in this study.

Finite Element Analysis (FEA) is a computer simulation technique using the FEM to carry out engineering analysis. There are many propriety FEA software packages. However, they are very expensive to purchase. Development of the finite element method in structural mechanics is usually based on an energy principle such as the virtual work principle or the minimum total potential energy principle. The finite element analysis from the mathematical side was first developed in 1943 by Richard Courant, who used the Ritz method of numerical analysis and minimization of variational calculus to obtain approximate solutions to vibration systems [1]. From the engineering side, the finite element analysis originated as the displacement method of the matrix structural analysis, which emerged over the course of several decades mainly in British aerospace research as a variant suitable for computers. Common existing FEA software include: ABAQUS, ANSYS, CAEFEM, COMSOL Multiphysics, FEA-Based Optimization, FEMdesigner, NASTRAN, PERMAS, CATIA, SolidWorks, etc.

The FEM has been successfully applied to the various practical problems of civil engineering (bridge deck analysis, plane truss, space frame and multi-storey building) and mechanical engineering (aircraft, motor vehicle, turbine blade and housing). Maximov et al. [2] employed isotropic plastic hardening and Von Mises yielding criterion for finite element simulation of spherical mandrelling process of holes with cracks. Yorgun et al. [3] investigated, by experimental and finite element modelling, the behaviour of a double channel beam-to-column connection subjected to in plane bending moment and shear. Simulation of the tests was carried out by means of a nonlinear finite element software ANSYS. Sutherland [4] described the use of a finite element computer code "AXICRP" developed for solving creep problems for plane stress, plane strain, and axisymmetric bodies of revolution. Arya [5] investigated the feasibility of using a viscoplastic model to perform a nonlinear structural analysis. He compared the analytical and FE solutions of three classical problems, viz. a pressurized thick-walled cylinder, a thin rotating disk and a pressurized thick-walled sphere.

Victor and Bikramjit [6] compared numerical results with ANSYS 15.0 results with differences being insignificant. Nirmall and Vimala [7] cantilever beam and tapered cantilever beam, of different sizes were prepared for experimental purpose of free vibration analysis of beams made with different materials such as aluminum, brass and mild steel. The natural frequency of the beams obtained 
from experimental and theoretical methods were compared with harmonic analysis using ANSYS software. Chaphalkar et al. [8] focuses on the numerical analysis and experimental analysis of transverse vibration of fixed free beam and investigates the mode shape frequency. All the frequency values are analysed with the numerical approach method by using ANSYS package.

Many authors have, on separate basis, carried out study on the finite element analysis of plate bending, using different triangular meshes, and different patterns of presentation of the results [9-11]. There are many propriety FEA software packages. However, they are very expensive to purchase. The objective of this study is to develop an interactive computer-based package for the analysis of deflection on a cantilever beam, and also to investigate the variation of results due to change in the degree of discretisation of the domain.

\section{THEORETICAL BASIS OF THE MODEL}

\section{A. Exact Solution of Deflection on a Cantilever Beam}

The derived displacement function for deflection along the neutral plane (displacement along y-axis) for a beam in Fig. 1 derived by Bamiro [12] is

$$
\delta(x, 0)=\frac{v P x y^{2}}{2 E I}-\frac{P L^{2} x}{2 E I}+\frac{P x^{3}}{6 E I}+\frac{P L^{3}}{3 E I}
$$

where $v=$ Poisson's ratio, $P=$ Load applied to the beam, $E=$ Modulus of Elasticity,

$I=S e c o n d$ moment of area, and $L=$ Length of the beam.

The deflection will have a maximum value as derived by Bamiro [12] in (2).

$$
\delta(x, 0)=\frac{P L^{3}}{3 E I} \text { at } \mathrm{x}=0
$$

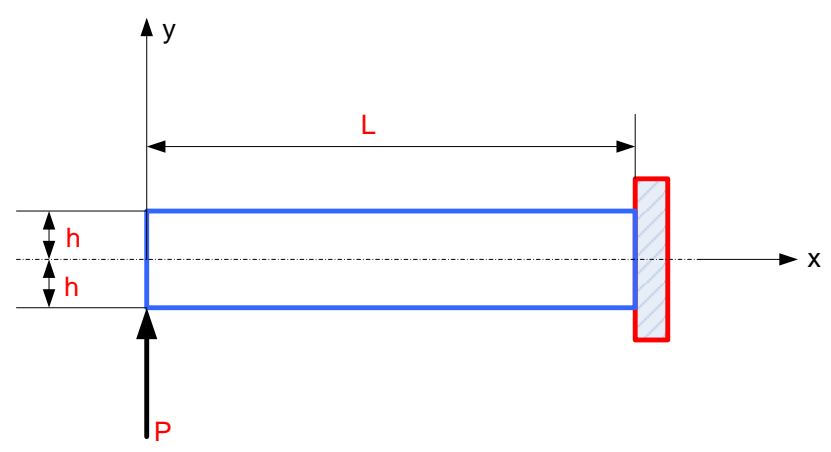

Fig. 1. A unit-width cantilever beam with a point load

\section{B. FEM Solution of Deflection on a Cantilever Beam}

For the development of the model, the following major steps were employed:

\section{Step 1: Idealization and discretization}

The idealization, shown in Fig. 2 and 3, gives the following information (taking the origin of the coordinate system as node 1) (i) Type of element: linear strain triangular (LST) of uniform thickness;

(ii) Number of elements: 4 and 10.

(iii) Number of nodes per element: 6 .

(iv) All elements are isotropic, homogeneous and obey Hooke's law.

(v) At each of the six nodes there are two degrees of freedom. For example, at node 3 there is a horizontal deflection component $\mathrm{u}_{3}$ and a vertical deflection component $\mathrm{v}_{3}$

(vi) The Boundary Conditions (BC) is specified as follows:

For 4-element mesh, $u_{10}=v_{10}=u_{15}=v_{15}=u_{13}=v_{13}=0$

For 10-element mesh $u_{28}=v_{28}=u_{33}=v_{33}=u_{31}=v_{31}=0$

where

$u=$ In-plane displacement in $x$ direction and $v=$ In-plane displacement in $y$ direction.

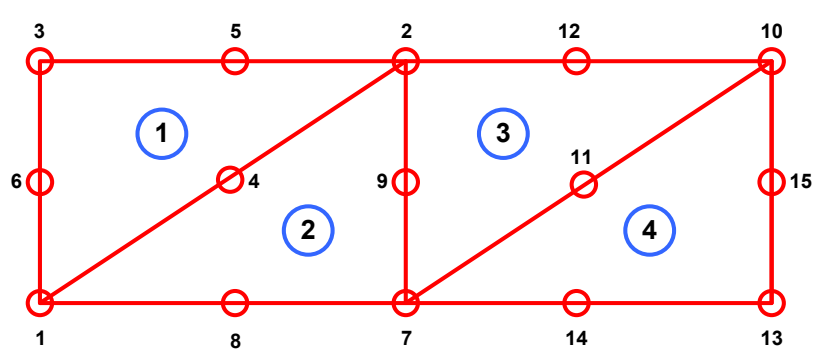

Fig. 2. Four-element mesh

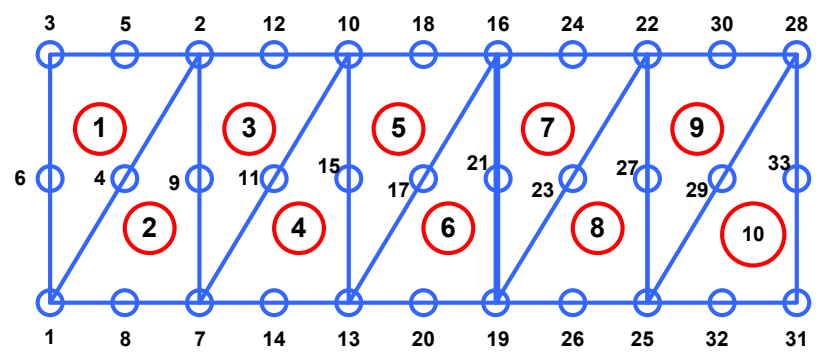

Fig. 3. Ten-element mesh

The unknown nodal displacements are now given by

$$
\{d\}=\left\{\begin{array}{l}
\frac{d_{1}}{d_{2}} \\
\underline{d_{3}} \\
\underline{d_{4}} \\
\underline{d_{5}} \\
\underline{d_{6}}
\end{array}\right\}=\left\{\begin{array}{c}
u_{1} \\
v_{1} \\
u_{2} \\
v_{2} \\
u_{3} \\
v_{3} \\
u_{4} \\
v_{4} \\
u_{5} \\
v_{5} \\
u_{6} \\
v_{6}
\end{array}\right\}
$$


Step 2: Selecting a Displacement Function

A quadratic displacement function in each element as

$u(x, y)=a_{1}+a_{2} x+a_{3} y+a_{4} x^{2}+a_{5} x y+a_{6} y^{2}$

$v(x, y)=a_{7}+a_{8} x+a_{9} y+a_{10} x^{2}+a_{11} x y+a_{12} y^{2}$

This can be expressed in matrix form as

$\{\psi\}=\left\{\begin{array}{l}u \\ v\end{array}\right\}=\left[\begin{array}{cccccccccccc}1 & x & y & x^{2} & x y & y^{2} & 0 & 0 & 0 & 0 & 0 & 0 \\ 0 & 0 & 0 & 0 & 0 & 0 & 1 & x & y & x^{2} & x y & y^{2}\end{array}\right]\left\{\begin{array}{l}a_{1} \\ a_{2} \\ \cdot \\ \cdot \\ \cdot \\ a_{12}\end{array}\right\}$

Alternatively, (7) is expressed as

$$
\{\psi\}=[M *]\{a\}
$$

The coefficients $a_{1}$ through $a_{12}$ can be obtained by substituting the coordinates into (5) and (6) and solving for $\mathrm{a}_{\mathrm{i}}{ }^{\text {'s }} \mathrm{s}$ as follows:

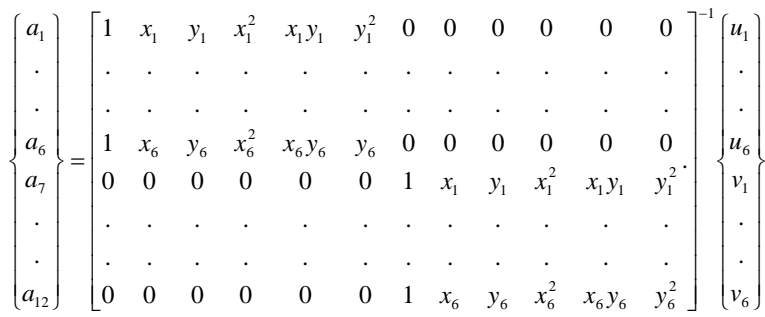

(9)

Alternatively, (9) is expressed as

$$
\{a\}=[X]^{-1}\{d\}
$$

where $[X]$ is a $12 \times 12$ matrix.

Then the $\mathrm{a}_{\mathrm{i}}$ s, in terms of nodal displacements, are substituted into (8) and the general displacement expressions in terms of the shape functions and the nodal degree of freedom as,

$$
\{\psi\}=[N]\{d\}
$$

where,

$$
[N]=\left[M *[X]^{-1}\right.
$$

\section{Step 3: Define the Strain and Stress Relationships}

Element strains and stresses are expressed in terms of the unknown nodal displacements. The strains associated with the two-dimensional element are given by Fenner [13] as

$$
\{\varepsilon\}=\left\{\begin{array}{c}
\varepsilon_{x} \\
\varepsilon_{y} \\
\gamma_{x y}
\end{array}\right\}=\left\{\begin{array}{c}
\frac{\partial u}{\partial x} \\
\frac{\partial v}{\partial y} \\
\frac{\partial v}{\partial x}+\frac{\partial u}{\partial y}
\end{array}\right\}
$$

Using (7) in (13),

$\{\varepsilon\}=\left[\begin{array}{cccccccccccc}0 & 1 & 0 & 2 x & y & 0 & 0 & 0 & 0 & 0 & 0 & 0 \\ 0 & 0 & 0 & 0 & 0 & 0 & 0 & 0 & 1 & 0 & x & 2 y \\ 0 & 0 & 1 & 0 & x & 2 y & 0 & 1 & 0 & 2 x & y & 0\end{array}\right]\left\{\begin{array}{c}a_{1} \\ a_{2} \\ \cdot \\ \cdot \\ a_{12}\end{array}\right\}$

Rewriting (14) as

$$
\{\varepsilon\}=\left[M^{\prime}\right]\{a\}
$$

Substituting (9) for $\mathrm{a}_{\mathrm{i}}$ 's into (15), $\{\varepsilon\}$ will be obtained in terms of nodal displacements as

$$
\{\varepsilon\}=[B]\{d\}
$$

where $[\mathrm{B}]$ is a function of the variables $\mathrm{x}$ and $\mathrm{y}$ and the coordinates $\left(\mathrm{x}_{1}, \mathrm{y}_{1}\right)$ through $\left(\mathrm{x}_{6}, \mathrm{y}_{6}\right)$ given by

$$
[B]=\left[M^{\prime}\right][X]^{-1} \text {. }
$$

In general, the in-plane stresses are given by Daryl [14] as

$$
\left\{\begin{array}{l}
\sigma_{x} \\
\sigma_{y} \\
\tau_{x y}
\end{array}\right\}=[D]\left\{\begin{array}{l}
\varepsilon_{x} \\
\varepsilon_{y} \\
\gamma_{x y}
\end{array}\right\}=[D][B]\{d\}
$$

where [D] is the constitutive matrix, and given as

$$
[D]=\frac{E}{1-v^{2}}\left[\begin{array}{ccc}
1 & v & 0 \\
v & 1 & 0 \\
0 & 0 & \frac{1-v}{2}
\end{array}\right]
$$

\section{Step 4: Generating Element Stiffness Matrix}

Using the principle of minimum potential energy, the equation for LST element is generated by Daryl [13] as

$$
[k]=\iiint_{V}[B]^{T}[D][B] d V
$$

where $V=$ Volume and $k=$ Element stiffness matrix.

\section{Step 5: Assembling the Global Stiffness Matrix}

The global structure stiffness matrix and equations is obtained by using the direct stiffness method as derived in Rockey et al. [15] as 


$$
[K]=\sum_{e=1}^{N}\left[k^{(e)}\right]
$$

and

$$
\{F\}=[K]\{d\}
$$

where $\{F\}=$ Nodal Force vector

\section{Step 6: Solving for the Nodal Displacements}

The unknown global structure nodal displacements are determined by solving the system of algebraic equations given by (22).

\section{Step 7: Calculating Deflection and Stresses}

Having solved for the nodal displacements, strains and stresses can be obtained in the global $\mathrm{x}$ and $\mathrm{y}$ directions in the elements by using (16) and (18) respectively.

\section{DEVELOPMENT OF THE FEA PACKAGE}

The common characteristic of all computer applications is their intrinsic ability to carry out complex mathematical computations at high speeds and at a very acceptable degree of accuracy. After critical scrutiny of available software developed on FEA for plate bending, the following features are embedded in the package:

(i) a user friendly interface, which presents an easy and FEA flow process data entry;

(ii) a visual presentation of the plate model whose solution is being sought;

(iii) progressive view of the data input; and

(iv) colour-code presentation of the generated output of the Finite Element Method solution

The package was developed on the platform of Visual BASIC 6.0. It involved the use of Visual Basic forms, modules and class modules. The forms contain the Graphical User Interface (GUI) objects; the modules contain the functions and subroutines; and the class modules contain user defined objects called classes. The flow of the program involves interaction between the GUI objects, the functions, subroutines and the classes. Fig. 4 shows a simplified framework of the model. Pre-processing stage involves discretization and collection of data needed for the analysis while post-processing stage involves presentation of output of the analysis. In the package, the results are made available in both textual and graphical forms. Codes for each form are attached on individual basis. The important forms in the model are Mainform, frmPlate Dimension, frmDivide, frmLoadBC, frmDisplacementBC, frmMaterialProperties, frmResults and frmPlotView.

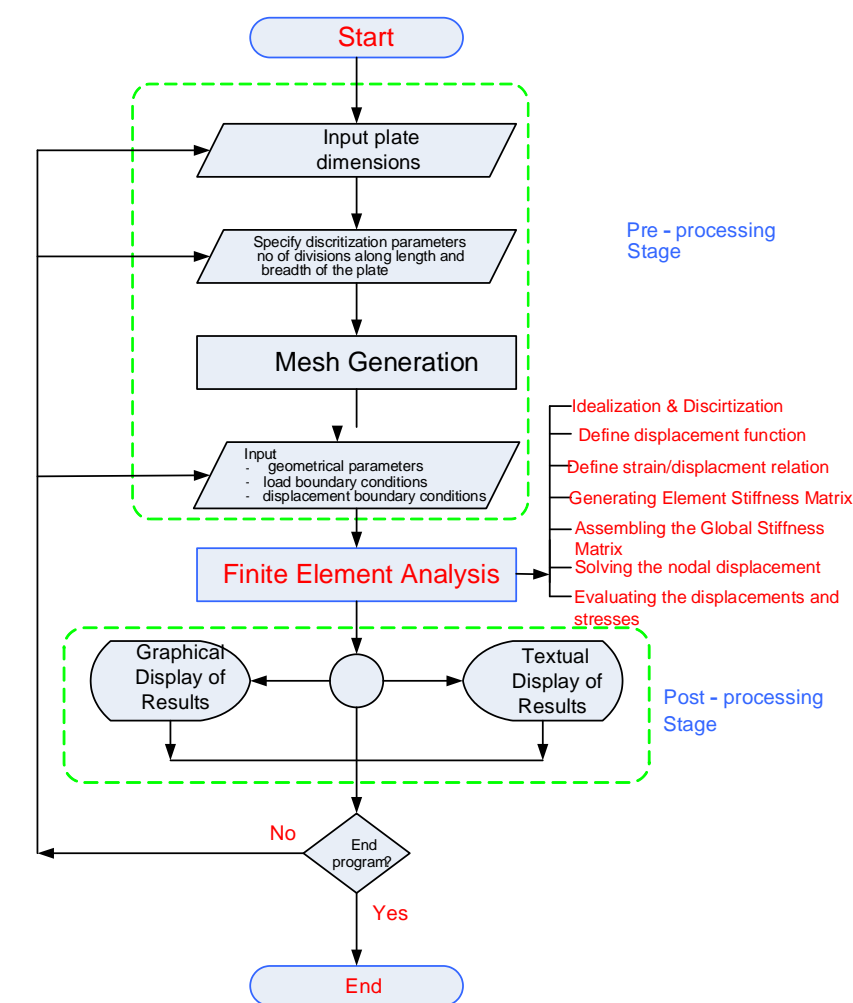

Fig. 4. Basic framework of the developed package

\section{Testing OF The PACKAGE}

In order to establish the accuracy of the model, it has been used to analyse deflection of a cantilever beam subjected to a point load at the extreme. This example has been chosen because an analytical solution can be easily obtained, and this provides a useful basis for the discussion of the accuracy of the numerical tool. The details of the case study are $\mathrm{P}=10 \mathrm{kN}, \mathrm{h}=1.0 \mathrm{~m}, \mathrm{~L}=10 \mathrm{~m}, v=0.3$, and $\mathrm{E}=2 \mathrm{x}$ $10^{11} \mathrm{~N} / \mathrm{m}^{2}$. The following steps were taken in the implementation of the model:

(i) Click the Draw button on the main form and enter the dimensions of the domain as shown in Fig. 5.

(ii) Click the divide button to specify number of divisions along $\mathrm{x}$ - and $\mathrm{y}$ - axes. A 4-element discretization is equivalent to four divisions along $\mathrm{x}$ axis and two divisions along $y$-axis as shown in Fig. 6. Click the generate mesh button to view the discretization.

(iii) Specify the load boundary condition: From the Assign menu, click Load BC, select the node 1 from the combo box, a green circle in the view port indicates the selected node. Click the y-component check box and enter the value of the force in Newton and click "Set". This is illustrated in Fig. 7a.

(iv) Specify the displacement boundary conditions: From the Assign menu, click Displacement BC, select the "Right" from the plate side combo box and click "Add", the retrained sides are indicated in the view port and the side right nodes numbers are displayed as in Fig. $7 b$.

(v) Specify the Modulus of elasticity and Poisson's ratio for the plate material. From Assign menu, click Material Properties, enter value of $\mathrm{E}$ and $v$ and click "set". This is illustrated in Fig. 8. 
(vi) Click the "Solve" button to initiate the analysis.

(vii) To view the textual results, click the "Textual Results Menu" and select the appropriate menu item corresponding to the desired view (Fig. 9).

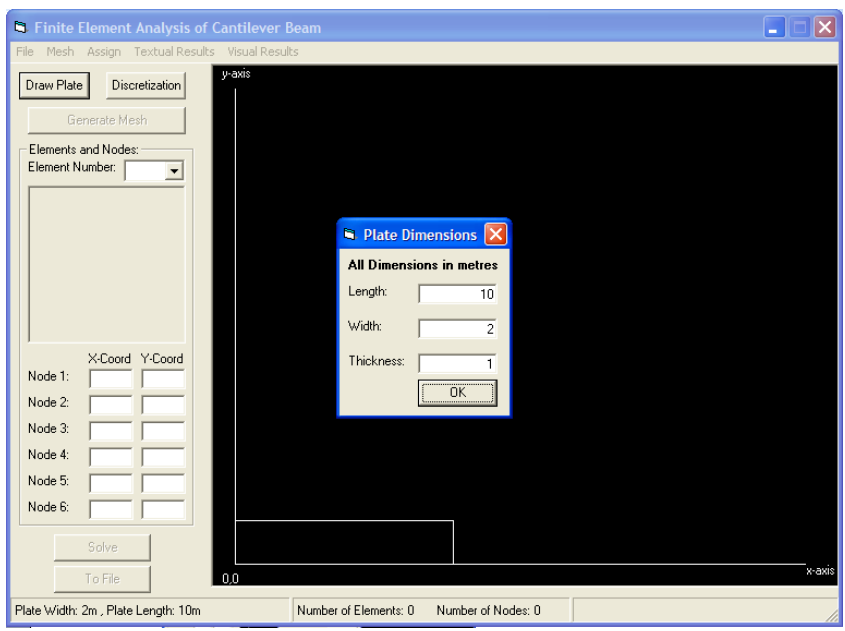

Fig. 5. Interface to define plate dimension

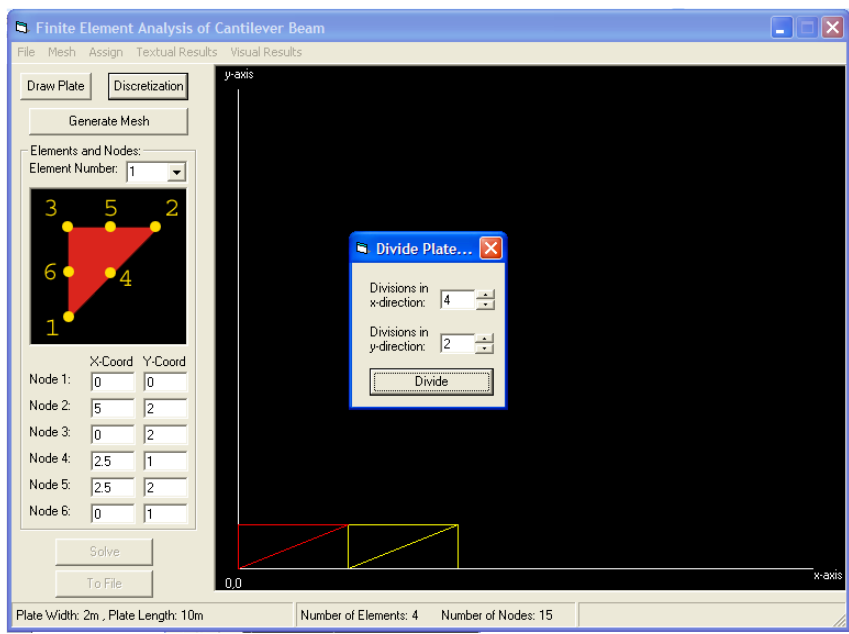

(a) 4 elements

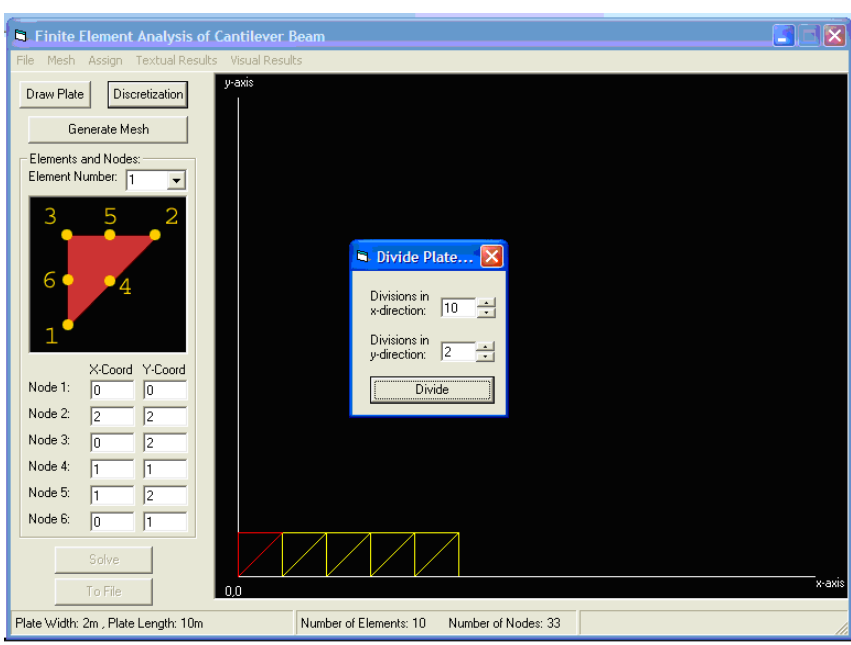

(b) 10 elements

Fig. 6. Interface showing element meshes

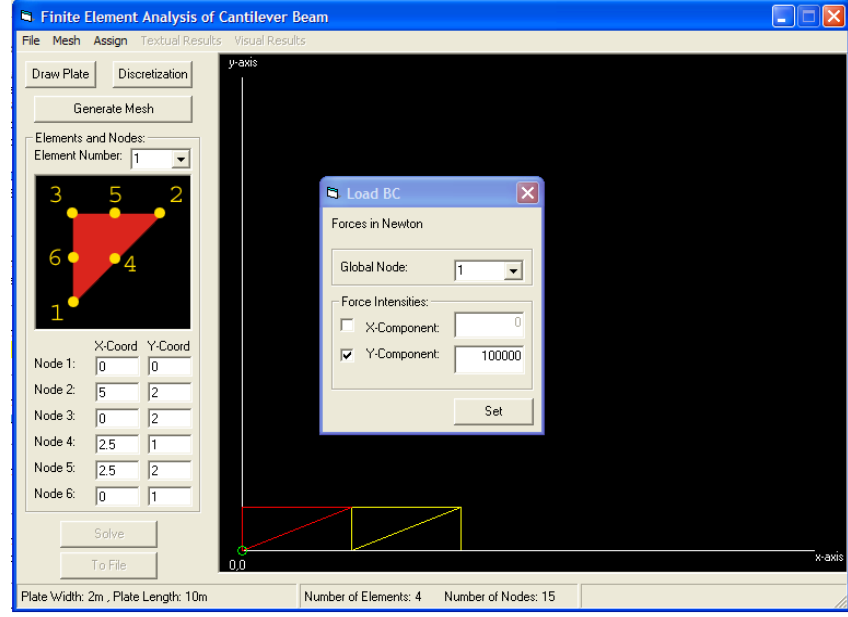

(a) Specification load BC

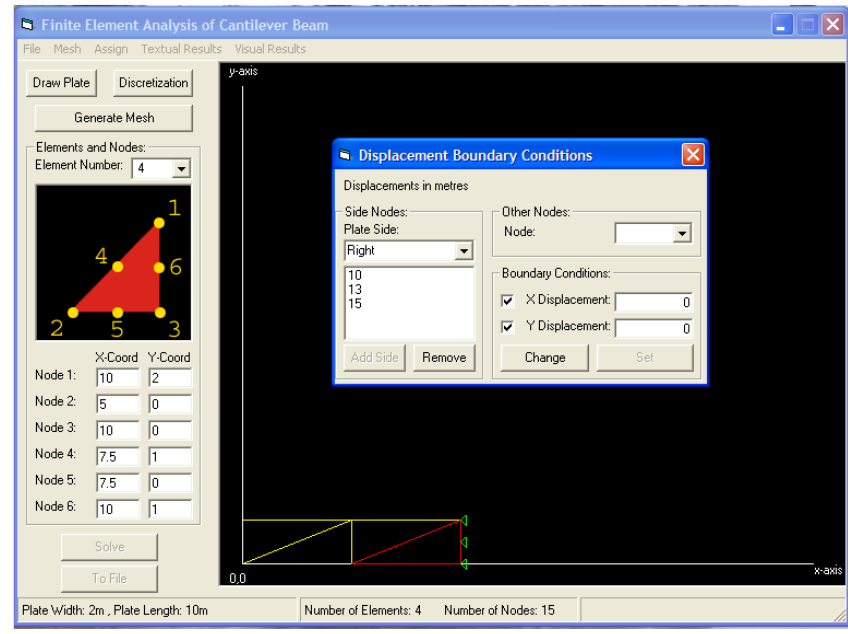

(b) Specification of displacement BC

Fig. 7. Interface to specify load intensity and boundary conditions for 4element mesh

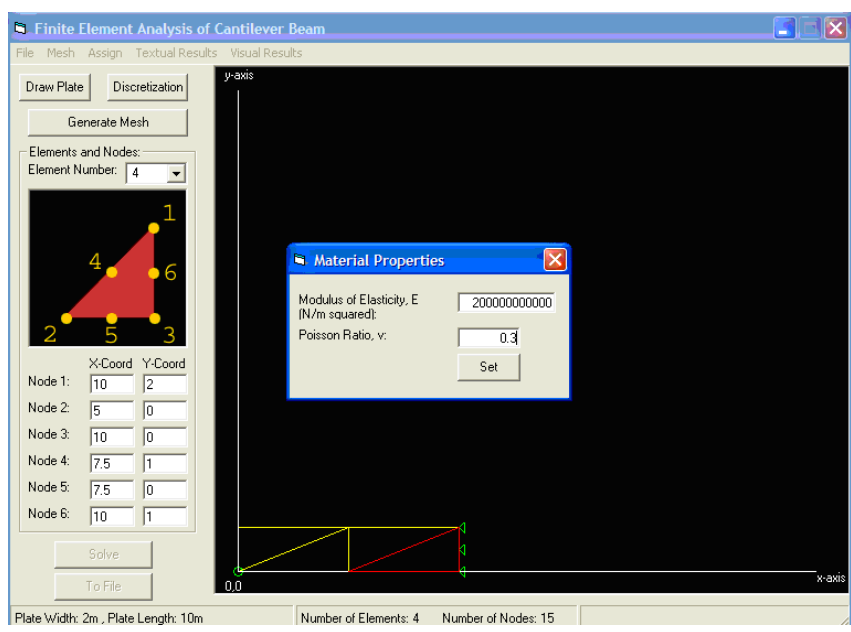

Fig. 8. Interface to specify material properties of the plate 


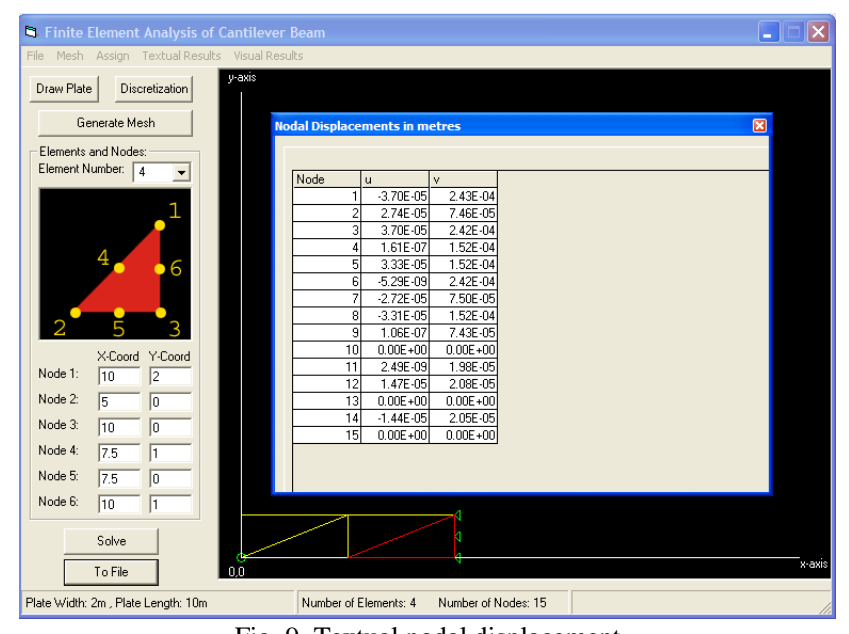

Fig. 9. Textual nodal displacement

\section{RESULTS AND DISCUSSION}

The deflections results were obtained for the cantilever problem using both four and ten triangular elements. The exact solutions were computed from (1) using the coordinates of the node along the neutral plane. The deflection curves for points along the neutral plane of the beam are presented in Fig. 10 and 11 using the exact solution and COMSOL Multiphysics software compared with 4-element and 10-element model results respectively.

It was observed from the Fig. 10 that the deflection results for the 4-element model were significantly far from the exact solution and COMSOL Multiphysics results while the 10-element model results almost coincide with that of the exact solution and COMSOL Multiphysics results (Fig. 11). This confirms the fact that the more the number of element, the better the results as reported in literature [11]. The present graphical displacement had the same configuration with COMSOL Multiphysics graphical displacement (Fig. 12). This implies that the model can used as alternative to the proprietary software.

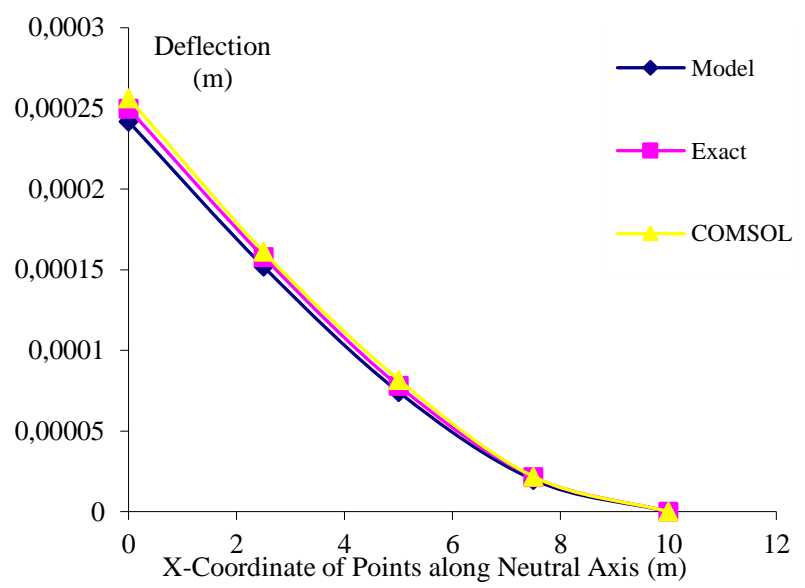

Fig. 10. Comparison of 4-Element Model with Exact Solution and COMSOL Multiphysics

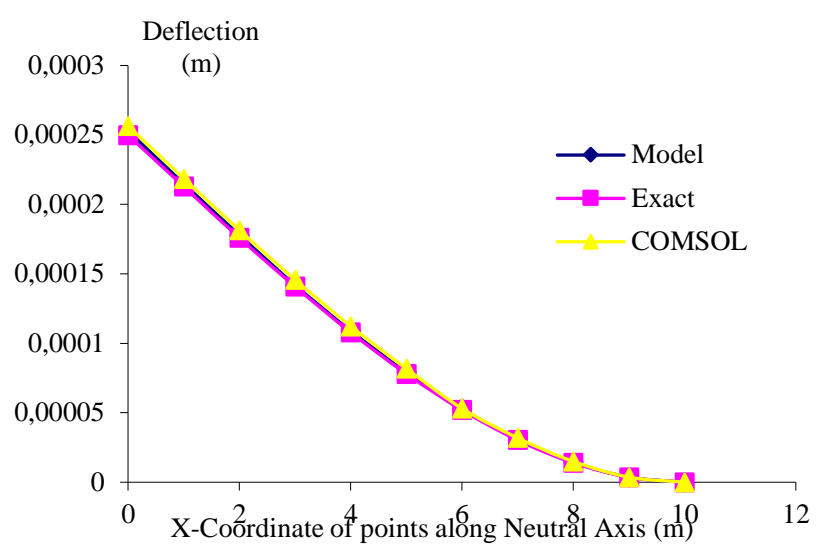

Fig. 11. Comparison of 10-Element Model with Exact Solution and COMSOL Multiphysics

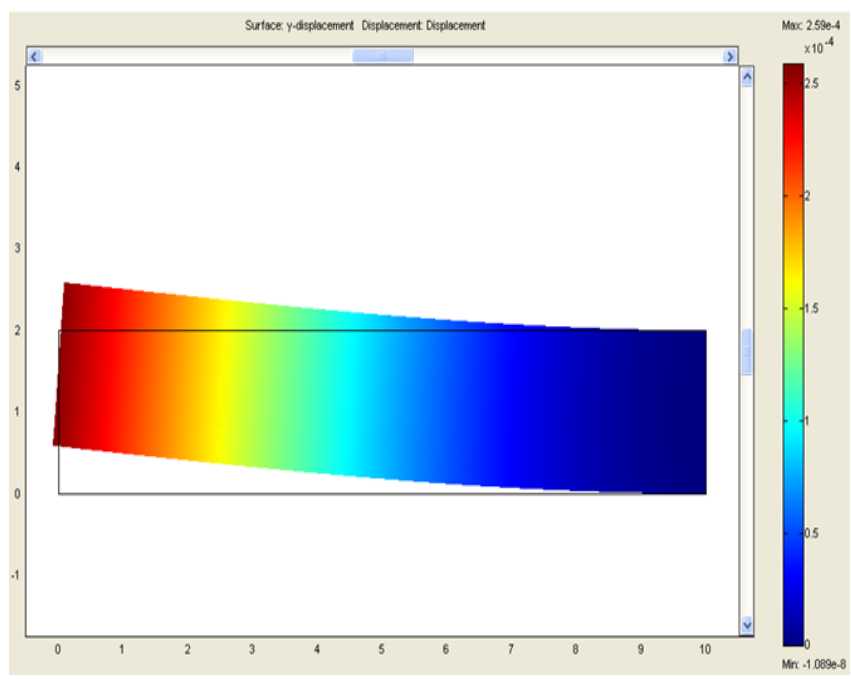

(a) COMSOL Multiphysics graphical

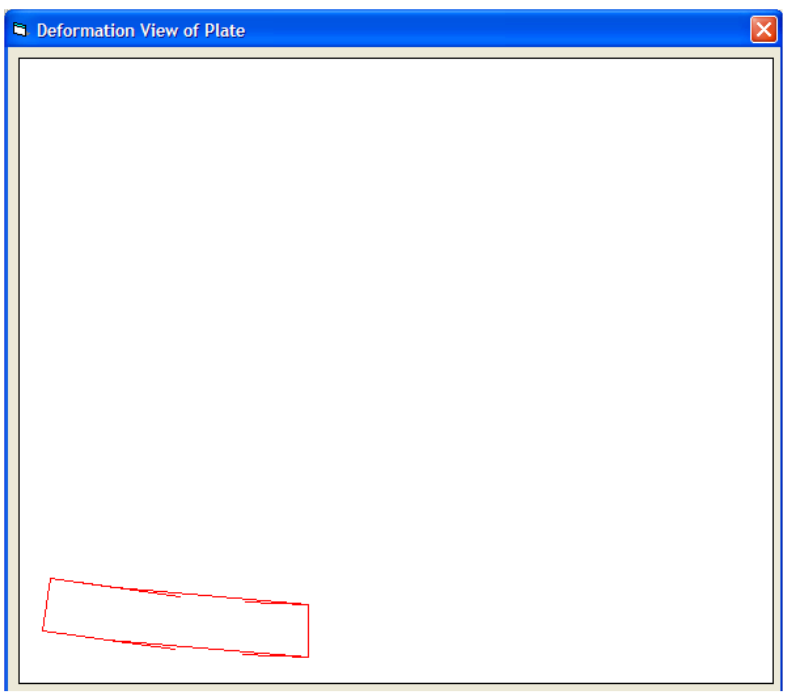

(b) Present model graphical displacement

Fig. 12. Graphical displacement results of the beam

\section{CONCLUSIONS}

The basic features of FEA have been presented in this study by developing a FE model using LST elements and applying it to analyse the deflection of cantilever beam. The model was developed with an interactive INPUT interface on Visual BASIC platform and a textual and graphical OUTPUT interfaces for better interpretation of results. The model was tested with 10-element and 4-element meshes 
and the results gave perfect match with the analytical solutions. The universal nature of the package is such that it can handle many cases that belong to 2-D plane elasticity category. All required are data input that reflect the imposed boundary conditions and proper identification of variables. Visualizing effects of various parameters on the behaviour of the physical system allows analysts to relate the system behaviour to the theoretical concepts. The model may serve as cheap instructional tool for learning in the field of numerical analysis.

\section{ACKNOWLEDGMENT}

The authors acknowledge the facilities support at Department of Mechanical Engineering, Obafemi Awolowo University, Ile-Ife and Department of Mechanical Engineering, University of Ibadan, Nigeria.

\section{CONFLICTS OF INTEREST}

The authors declare that there is no conflict of interest regarding the publication of this paper.

\section{REFERENCES}

[1] F. J. Williamson, "Richard courant and the finite element method: A further look," Historia Mathematica, vol.7, no. 4, pp. 369-378, November 1980.

[2] J. T. Maximov, T. V. Kuzmanov, A. P. Anchev and M. D. I. Ichkova, "A finite element simulation of the spherical mandrelling process of holes with cracks," Journal of Materials Processing Technology, vol. 171, no. 3, pp. 459-466, February 2006.

[3] C. Yorgun, S. Dalci, and G. A. Altay, "Finite element modelling of bolted steel connections designed by double channel," Computer and Structures, vol. 82, no. 29-30, pp. 2563-2571, November 2004.

[4] W. H. Sutherland, "AXICRP - finite element computer code for creep analysis of plane stress, plane strain and axisymmetric bodies," Nuclear Engineering and Design, vol. 11, no. 2, pp. 269-285, March 1970.

[5] V. K. Arya, "Analytical and finite element solutions of some problems using a viscoplastic model," Computers and Structures, vol. 33, no. 4, pp. 957-967, 1989.

[6] D. Victor and D. Bikramjit, "Deflection and stress analysis of a beam on different elements using ANSYS APDL," International Journal of Mechanical Engineering and Technology, (IJMET), vol. 5, no. 6, pp. 70-79, June 2014.

[7] T. Nirmall and S. Vimala, "Free vibration analysis of cantilever beam of different materials," International Journal of Applied Engineering Research, vol. 5, no. 4, pp. 612-615, April 2016.

[8] S. P. Chaphalkar, N. K. Subhash and M. M. Arun, "Modal analysis of cantilever beam structure using finite element analysis and experimental analysis," American Journal of Engineering Research, (AJER), vol. 4, no. 10, pp. 178-185, 2015.

[9] O. A. Bamiro, "The Finite element method: Basic concepts and procedures in engineering stress analysis," presented at a workshop organized by the Nigerian Society of Engineers, Ibadan Branch, Nigeria, 1982.

[10] O. Okunola, "Finite Element for plate bending using the Linear Strain Triangular element," M.Sc. Project, Dept. of Mech. Eng., Univ. of Ibadan, Nigeria, 2005.

[11] W. H. Bowes and L. T. Russel, Stress Analysis by the Finite Element Method for Practicing Engineers. London: Lexington Books, 1975, pp. 27-83.
[12] O. A. Bamiro, Mechanics and Strength of Deformable Materials. Abuja: Tertiary Education Trust Fund/Ibadan University Press, 2014 pp. 489-583.

[13] R. T. Fenner, Mechanics of Solids, Boston Melbourne: Blackwell Scientific Publications, 1998, pp. 100-136.

[14] L. L. Daryl, A First Course in the Finite Element Method, 5th ed. Stamford: Cengage Learning, 2012, pp. 166-234.

[15] K. C. Rockey, H. R. Evans, D. W. Griffiths and D. A Nethercot, The Finite Element Method: A Basic Introduction for Engineers, New York: Granada Publishing Limited, 1999, pp. 177-192.

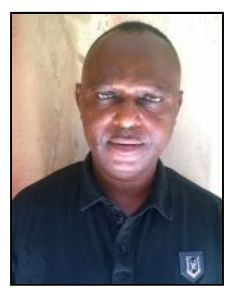

Kolawole A. Oladejo was born in Ibadan, Nigeria on 21 September, 1969. He has B.Eng. Mechanical Engineering from University of Ilorin, Nigeria in 1995; M.Sc. Mechanical Engineering from University of Ibadan, Nigeria in 1999; and Ph.D. Mechanical Engineering from University of Ibadan, Nigeria in 2011. His area of specialization is solid mechanics.

He works as a SENIOR LECTURER in Department of Mechanical Engineering, Obafemi Awolowo University, Ile-Ife, Nigeria. His current research interest is finite element in analysis and design, and computational mechanics while his previous research interests are manufacturing and heat transfer.

Dr. Oladejo is a member of Nigerian Institution of Mechanical Engineers (NIMechE); a member of Nigerian Society of Engineers (NSE); an academic member of American Gear Manufacturers Association (AGMA); and a registered engineer by Council for the Regulation of Engineering in Nigeria (COREN). He has the following awards: University of Ilorin Scholar Award; and UNESCO/ANSTI Award.

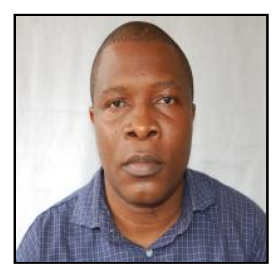

Rahaman Abu was born in Ibadan, Nigeria on 7 December, 1975. He has B.Sc. Mechanical Engineering from University of Ibadan, Nigeria in 2001; M.Sc. Mechanical Engineering from University of Ibadan, Nigeria in 2005; and Ph.D. Mechanical Engineering from University of Ibadan, Nigeria in 2015. His area of specialization is solid mechanics.

$\mathrm{He}$ works as a LECTURER in Department of Mechanical Engineering, University of Ibadan, Nigeria. His current research interest is finite element design and analysis while his previous research interests are energy studies and heat transfer.

Dr. Abu is a member of Nigerian Society of Engineers (NSE) and registered engineer by Council for the Regulation of Engineering in Nigeria (COREN). He has TETFund Academic Staff Training and Development (AST\&D) award; and Andersen Honours List Award.

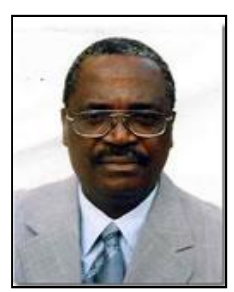

Olufemi A. Bamiro was born in Ogun State, Nigeria on 16 September, 1947. He has B.Sc. Mechanical Engineering from Nottingham University, Nottingham, England in 1971; and Ph.D. Mechanical Engineering from McGill University, Montreal, Canada in 1975. His area of specialization is solid mechanics.

$\mathrm{He}$ is a Professor in Department of Mechanical Engineering, University of Ibadan, Nigeria. His current research interest is biomedical engineering and finite element design and analysis while his previous research interests are energy studies, applied mechanics and manufacturing.

Prof. Bamiro is a member of Nigerian Society of Engineers (NSE); a member of Solar Energy Society of Nigeria (SESN); and registered engineer by Council for the Regulation of Engineering in Nigeria (COREN). He has distinguished Shell Scholar Award; and award of Excellence in recognition of contributions to Engineering profession. 